\title{
O BRASIL NO ESPELHO DA CHINA: TENDÊNCIAS PARA O PERÍODO PÓS-CRISE FINANCEIRA GLOBAL*
}

\author{
André Moreira Cunha ${ }^{a}$ \\ Marcos Tadeu Caputi Lélis ${ }^{b}$ \\ Julimar da Silva Bichara ${ }^{c}$
}

RESUMO: Este trabalho analisa como a reação do governo chinês à crise financeira global afetou a América Latina, particularmente o Brasil. A despeito das intenções de reorientação do seu modelo de crescimento, a resposta chinesa à crise reforçou, pelo menos a curto e médio prazos, a dependência das exportações e dos investimentos. Em um quadro de lenta recuperação das economias centrais, passa ganhar destaque o acesso a mercados mais dinâmicos, como os países emergentes. Assim, para além do papel de fornecedora de recursos naturais, as economias latino-americanas passam a ter uma importância renovada como destino das exportações de manufaturas e capitais chineses. Países com estruturas produtivas mais maduras e diversificadas, como o Brasil, irão deparar-se com o risco de um processo de regressão em seus padrões de especialização.

PALAVRAS-CHAVE: China; Brasil; crise financeira global; estratégia de desenvolvimento.

CLASSIFICAÇÃO JEL: F59; F44; O54.

\footnotetext{
* Artigo recebido em 15/03/2012 e aprovado em 06/08/2012.

${ }^{\text {a }}$ Doutor em Economia pela Universidade Estadual de Campinas (UNICAMP), professor do Programa de Pósgraduação em Economia da Universidade Federal do Rio Grande do Sul (PPGE-UFRGS) e pesquisador do Conselho Nacional de Desenvolvimento Científico e Tecnológico (CNPq). Contato: andre.cunha@ufrgs.br. ${ }^{\mathrm{b}}$ Doutor em Economia pela UFRGS, professor da Unisinos e coordenador da Unidade de Inteligência Comercial e Competitiva da Agência Brasileira de Promoção de Exportações e Investimentos (APEX-Brasil). Contato: mcaputi@uol.com.br.

c Doutor em Economia pela Universidad Autónoma de Madrid e professor da mesma instituição. Contato: julimar.dasilva@uam.es.
} 


\title{
BRAZIL AS A MIRROR OF CHINA: NEW TRENDS AFTER THE GLOBAL FINANCIAL CRISIS
}

\begin{abstract}
This paper analyses how China's response to the global financial crisis (GFC) has affected Latin American countries, particularly Brazil. We argue that, despite the intentions of a growth model re-orientation, Chinese policymakers' response to the GFC, at least in the short and medium terms, will reinforce the previous reliance on exports and investments. Considering the sluggish recovery in advanced economies, that strategy will amplify Chinese pressures to access dynamic domestic markets in emerging countries. In this context, Latin America will represent not only a source of natural resources, but also an increasingly important market for Chinese manufactured products. As a result, countries with more diverse productive might experience a regressive pattern of specialization.
\end{abstract}

KEYWORDS: China; Brazil; global financial crisis; development. 


\section{INTRODUÇÃO}

Este trabalho parte do argumento de que a recuperação recente do dinamismo da economia brasileira tem ocorrido em um ambiente externo de mudanças estruturais provocadas, principalmente, pela ascensão chinesa (Castro, 2008; Castro e Castro, 2011). As oportunidades e os riscos associados a esse processo devem ser ponderados com cautela pelos estrategistas brasileiros, na medida em que a economia nacional emerge de um quarto de século de semiestagnação e apresenta fortes deficiências competitivas. Sugere-se aqui que o ambiente pós-crise financeira global revela uma China mais próativa na busca de mercados capazes de compensar o declínio relativo na demanda das economias centrais, e de ativos estratégicos que permitam, por meio do investimento direto externo (IDE), acessar fontes de recursos naturais, tecnologias e mercados.

Busca-se verificar algumas implicações da ascensão chinesa sobre as economias latino-americanas em geral, e a economia brasileira em particular, enfatizando o período pós-crise financeira global. Conforme destacado por Phillips (2011), as relações sino-latino-americanas vêm evoluindo de forma tão intensa, que os pesquisadores se veem diante do desafio da constante revisão e atualização de dados e hipóteses. Phillips (2011) enfatiza que os trabalhos mais influentes publicados entre 2008 e 2010 sequer trataram da questão dos impactos da crise financeira global (CFG) sobre a estratégia chinesa de desenvolvimento e internacionalização e, por decorrência, dos efeitos destas sobre as diversas regiões e os setores de atividade.

Para atingir o objetivo proposto, assume-se a seguinte hipótese: as respostas do governo chinês à CFG e o ambiente de baixo dinamismo nas economias maduras tendem a reforçar a busca pelas empresas chinesas de novos mercados e oportunidades de investimento, o que coloca a América Latina como importante alvo para a internacionalização da China. Assim, espera-se encontrar ampliação na diversificação das exportações em termos de produtos e mercados de destino, e concentração de seus investimentos nas regiões emergentes.

De fato, este trabalho avança nesse sentido e mostra que, dentre outras coisas, a crise gerou a necessidade de a China diversificar mercados para suas exportações, bem como criou a oportunidade para a extroversão de seus capitais. Tais vínculos têm estreitado as interações cíclicas entre as economias da região e a China (Calderón, 2008; CesaBianchi et al., 2011; IADB, 2012). Verifica-se, com base na aplicação da metodologia desenvolvida por Frankel e Rose (1998), que há crescente convergência entre os ciclos de negócios da economia brasileira com a economia chinesa em função da maior intensidade do comércio bilateral. Ademais, os indicadores de desempenho comercial e de intensidade de investimentos sinalizam para a pertinência da nossa principal hipótese, vale dizer, que o período pós-crise revela uma China que intensifica sua presença na periferia capitalista, como forma de compensar a perda de dinamismo nas regiões 
centrais. Por decorrência, a competição com as exportações originadas na China (e, também, nos demais países asiáticos) podem colocar em xeque a capacidade competitiva de economias mais maduras diversificadas, especialmente México e Brasil ${ }^{1}$.

Além desta breve introdução, os argumentos estão estruturados da seguinte forma: a seção 2 revela as características gerais da modernização e internacionalização da economia chinesa, onde se procura enfatizar as tendências em conformação no período pós-CFG; a seção 3 explora as relações entre comércio e convergência dos ciclos econômicos, bem como introduz indicadores sobre o desempenho das exportações chinesas, de modo a evidenciar as tendências desenhadas na seção anterior; a seção 4 mostra que o desempenho da economia brasileira, especialmente no que se refere ao comércio internacional, pode ser percebido como refletindo, de forma inversa, o que acontece na China; seguem as considerações finais.

\section{A ESTRATÉGIA CHINESA DE DESENVOLVIMENTO E INTERNACIONALIZAÇÃO: QUAL O PAPEL DA AMÉRICA LATINA?}

Desde o final dos anos 1970, sob o guarda-chuva da estratégia de Deng Xiaoping de reformas e abertura econômica ${ }^{2}$, a China ressurge como potência global. O rápido crescimento econômico e o intenso processo de internacionalização fizeram com que, em 2011, sua economia contribuísse com mais de $10 \%$ do comércio global, $10 \%$ do produto interno bruto (PIB) mundial medido em preços de mercado e $15 \%$ do PIB mundial medido em poder de paridade de compra. Além disso, a potência asiática se converteu em importante ator nos mercados financeiros internacionais, detendo mais de US $\$ 3$ trilhões de reservas internacionais e US $\$ 300$ bilhões em IDE. Em decorrência, o país tornou-se o segundo maior credor líquido do mundo ${ }^{3}$. Ademais, cabe mencionar que, desde o início dos anos 2000, os laços comerciais e financeiros entre China e América Latina vêm se estreitando, em um movimento que ganhou força depois de 2008. O comércio de mercadorias e o investimento direto chinês na região tem se expandido rapidamente, e a demanda chinesa por commodities constitui-se em fonte de dinamismo para os países ricos em recursos naturais (CEPAL, 2011a, 2011b; Bittencourt, 2012; Rosales e Kuwayama, 2012).

A resposta chinesa à CFG se expressou por meio de massivo estímulo monetário e fiscal (FMI, 2010, 2011). Apesar da desaceleração de seu crescimento econômico, é

\footnotetext{
${ }^{1}$ Ver, dentre outros, CEPAL (2011a), Bittencourt (2012) e Rosales e Kuwayama (2012).

${ }^{2}$ Ver, dentre outros, Zheng Bijian (2005), Kang (2007), Naughton (2007), Kurlantzick (2007), National Intelligence Council (2008), Yufan Hao et al. (2009), Halper (2010), Kissinger (2011). Ver também The Economist (27/12/2011).

${ }^{3}$ Ver Morrison e Labonte (2011, p. 2).
} 
razoável assumir que a expansão do consumo interno chinês e os novos fluxos de investimento do país possam tornar-se o novo motor do crescimento global (CEPAL, 2011a, 2011b). Para efeitos do presente trabalho, cabe salientar que, por um lado, isso significa que, nos anos vindouros, o crescimento da América Latina vai depender da sua habilidade em manter ou reforçar vínculos comerciais e de investimento com a China; por outro lado, considerada a baixa demanda nos países desenvolvidos, a China tem direcionado suas exportações para mercados emergentes que preservaram dinamismo econômico, o que vem intensificando a pressão competitiva sobre os produtores locais. Essa dimensão do chamado "efeito China" pode ser percebida como grande ameaça a países com setor manufatureiro robusto e diversificado, como Brasil e México.

Os impactos da CFG na China serão cruciais para a evolução de seu relacionamento com a América Latina. Aqueles que criticam o padrão de desenvolvimento chinês têm enfatizado suas vulnerabilidades, particularmente o que se assume ser um viés autoritário, a superexploração da mão de obra e do meio ambiente, a crescente desigualdade social, o nacionalismo, a corrupção, dentre outros (Babones, 2011; Clark, 2011). Em um contexto de lenta recuperação da economia global, particularmente nos países desenvolvidos, e assumindo a possibilidade de menor crescimento econômico chinês, enfatiza-se que há riscos de maior instabilidade social capaz de minar o status quo político. Esse cenário coloca em perspectiva a "frágil superpotência" (Shirk, 2007) e poderia explicar a rápida e determinada ação dos formuladores de política chineses frente à crise de 2008.

Se aqueles que argumentam que, nas próximas décadas, o eixo da economia global deslocar-se-á para o Leste, particularmente para a China, estiverem corretos ${ }^{4}$, deve-se questionar que papel caberia à América Latina neste novo cenário. A literatura recente explora a possibilidade de a região cristalizar um padrão de relacionamento do tipo Norte-Sul, o que implicaria em crescente especialização na produção e exportação de alimentos, minérios e energia, in natura ou com baixos níveis de processamento industrial. Isso colocaria em xeque o esforço de décadas para a conformação de estruturas produtivas mais densas e diversificadas, particularmente em países como Brasil e México ${ }^{5}$.

A despeito desta perspectiva, assume-se aqui que os resultados dessa interação vão depender, especialmente, de como os países latino-americanos vão responder à presença chinesa na região, o que significa que não há, necessariamente, um único padrão de relacionamento. Aqueles países que se preparam com uma renovada estratégia de

\footnotetext{
${ }^{4}$ Ver, dentre outros, Castro (2008), National Intelligence Council (2008), Yufan Hao, Wei e Ditter (2009), Halper (2010) e Subramanian (2011).

${ }^{5}$ Para uma maior discussão, ver Leão, Pinto e Acioly (2011).
} 
desenvolvimento estarão em melhores condições para maximizar os estímulos positivos da ascensão chinesa. Por outro lado, a passividade poderá contribuir para que se imponham soluções de "mercado", com resultados estruturais potencialmente problemáticos, como sugere a literatura concernente à "maldição dos recursos naturais" e outros problemas relacionados, como a doença holandesa e a desindustrialização ${ }^{6}$.

Assim, países como o Brasil se confrontam com a necessidade de gerir os estímulos potencialmente positivos da ascensão chinesa, especialmente o aumento na demanda por recursos naturais e a existência de recursos para investimentos, e, ao mesmo tempo, as pressões concorrenciais sobre os mercados internos e terceiros mercados. Essa clivagem oportunidade-ameaça deve ser enfrentada a partir de uma estratégia de desenvolvimento de longo prazo capaz de nortear as políticas públicas (Castro e Castro, 2011).

Esse desafio brasileiro insere-se no quadro mais geral de transformações na ordem econômica e política internacional. Nesta primeira década do século XXI, e com mais intensidade a partir da crise financeira global, economistas, cientistas políticos e formuladores de política têm discutido intensamente se o século XXI assistirá a uma disputa pela hegemonia global entre EUA, supostamente - para alguns, uma potência em declínio -, e a China, a potência em ascensão (Clark, 2011; Jacques, 2012). Os estrategistas chineses e especialistas da academia têm sustentado que esse reposicionamento não só é legítimo, dada a importância do país, como será pacífico e benéfico à comunidade internacional. Vislumbram uma ordem internacional multipolar e com maior compartilhamento de responsabilidades (Kang, 2007; Zheng Bijian, 2006, 2005; Wu Jiglian, 2006, 2005; Angang Hu, 2010).

A manutenção de um elevado ritmo de crescimento econômico e a presença nos diversos mercados de bens e fatores no plano internacional são encaradas por diversos analistas como um risco para a posição hegemônica dos EUA (Halper, 2010; Subramanian, 2011; Jacques, 2012). Por um lado, a força econômica poderia se traduzir em crescente capacidade militar, por outro, o exercício da "diplomacia econômica" ampliaria a capacidade chinesa de projetar poder. A China tem se consolidado como um dos principais parceiros comerciais e uma fonte de financiamento para várias nações em desenvolvimento. Sem as condicionalidades exigidas pelos governos ocidentais e pelas agências multilaterais, como o Fundo Monetário Internacional (FMI) e o Banco Mundial, o apoio chinês aos países periféricos tem sido um catalizador de influência e acesso privilegiado aos seus mercados e recursos naturais. Ademais, se o "Consenso de Washington" foi um fracasso

\footnotetext{
${ }^{6}$ Ver, dentre outros, Sachs e Warner (1997), Rowthorn e Wells (1987), Sinnot et al. (2010), Palma (2011, 2007), Bresser-Pereira (2010), IEDI $(2012,2011)$.

${ }^{7}$ Sobre o conceito de diplomacia econômica, ver Steil e Litan (2006).
} 
em termos de produzir crescimento com estabilidade macroeconômica, social e política, o "Consenso de Beijing", por combinar o poder dos mercados e da centralização política, poderia ser percebido como uma alternativa para acelerar o crescimento.

Nessas circunstâncias, Subramanian (2011) e Halper (2010) apontam que são elevados os riscos da China sobrepor os EUA, quer por virtudes próprias, quer pela crescente fragilidade econômica e política da atual superpotência. Para Mearsheimer (2010), isso poderia se dar em um ambiente de conflito crescente. Para Halper (2010), o principal risco vem da projeção internacional do modelo chinês, onde se combinam a forte centralização das decisões políticas em um Estado autoritário, com uma agressiva adesão aos mecanismos de mercado no mundo da produção, comercialização e finanças. Por sua vez, Subramanian (2011) enfatiza as fragilidades estadunidenses, potencializadas depois da crise: excesso de endividamento, crescente concentração na renda, esvaziamento da classe média e incapacidade do sistema político em prover soluções para os problemas econômicos. Há ainda quem considere que o poder chinês e suas perspectivas nas próximas décadas têm sido sobre-estimados (Babones, 2011; Clark, 2011).

Influentes analistas estadunidenses, como Nye Jr (2011), Kissinger (2011) e Ikenberry (2011), dentre outros, compartilham a perspectiva de que a ascensão chinesa não precisa, necessariamente, ser um sinônimo de ameaça ao poder de liderança dos EUA. Identificam que a potência asiática tem inúmeras fragilidades em seu modelo político e econômico, tanto do ponto de vista de sua sustentabilidade ambiental e pressões demográficas, quanto da capacidade de legitimação do poder central. Ainda assim, vislumbram a possibilidade de a China atuar ao lado dos EUA para o enfrentamento dos problemas globais. A manutenção de uma ordem democrática e aberta passaria, de um lado, pela capacidade dos EUA recuperarem o poder de influenciar as potências emergentes por meio de mecanismos não agressivos e, por outro, da disposição destes em atuar no sentido de fortalecimento das instituições e dos bens públicos globais. Em seus últimos planos quinquenais, especialmente o $12^{\circ}$ Plano Quinquenal de Desenvolvimento Econômico e Social (Casey e Koleski, 2011), que cobre o período 2011-2015, evidencia-se a preocupação dos estrategistas e das lideranças chinesas em renovar seu modelo de desenvolvimento. Maior ênfase no mercado interno e, portanto, a necessária redistribuição da renda e redução da propensão a poupar das famílias por meio de aumentos nos investimentos públicos na rede de proteção social e na sustentabilidade ambiental e energética são vetores essenciais do futuro em gestão. Ademais, para além de "fábrica do mundo", a China ambiciona ser fonte de inovações tecnológicas e geração de novos padrões de produção em consumo. Assim, o desafio colocado é o de transitar da etapa "Made in China" para a fase "Designed and Made in China" (Casey e Koleski, 2011; Nolan, 2011; Wong, 2011). Nos dois casos, a internacionalização de sua economia parece ser imprescindível (Jacques, 2012). 
Todavia, assim como nos planos anteriores, há uma potencial contradição entre o ritmo desejado de mudanças e a necessidade de geração de empregos e de expansão da renda. Estes últimos funcionam como estabilizadores sociais e legitimadores do status quo político. Assim, mesmo que a China migre para uma trajetória menos desequilibrada de desenvolvimento, não parece ser crível que isso se dê em um futuro próximo. Mais do mesmo é o que se pode esperar no curto prazo, vale dizer, utilização do drive exportador - em um mundo onde as economias maduras estão em crise e as periféricas tentam manter seu dinamismo - e de doses intensas de formação bruta de capital.

Portanto, antes de "crescer com base no mercado interno", a China seguirá buscando avançar nos mercados internacionais, especialmente em regiões com maior potencial de absorção de seus recursos, como na América Latina e África. Conforme destacado pela CEPAL (2011a, 2011b), a China é o hub regional de exportações. Por conta disso, o gigante asiático é deficitário no comércio com seus vizinhos mais desenvolvidos, especialmente Japão, Coreia do Sul e Taiwan, fornecedores de manufaturas intensivas em tecnologia, e também com as nações em desenvolvimento da região, especialmente os da Associação de Nações do Sudeste Asiático (ANSEA ou ASEAN, na sigla em inglês), recentemente beneficiados pelo acordo de livre comércio, que abastecem a China com recursos naturais - e, portanto, são concorrentes, em diversos segmentos, das economias latino-americanas e africanas que se situam na mesma faixa de fornecimento, sem se beneficiar dos termos daquele acordo.

Por fim, há de se considerar que o crescimento chinês entrou em uma nova etapa: após se consolidar como principal absorvedor de IDE entre as economias emergentes e, com isso, acelerar seu processo de modernização produtiva e inserção comercial nos mercados mundiais, governo e empresas, estatais ou privadas com fortes conexões com o poder central, estão se expandindo por meio do investimento direto no exterior. A China tem se convertido em importante exportador de capitais na forma de IDE, particularmente depois de 2005. Setores de energia e de recursos naturais diversos têm sido priorizados, bem como países que se caracterizam pela abundância relativa daqueles produtos e que estão localizados na Ásia, África, América Latina e no Oriente Médio.

O mapeamento preciso do volume e perfil do investimento chinês no exterior não é uma tarefa simples (Salidjanova, 2011; CEPAL, 2011a, 2011b). Além dos problemas não específicos à China, como a utilização de diferentes critérios de contabilização de fluxos e estoques de IDE e a canalização de recursos por meio de paraísos fiscais - recurso muito utilizado no caso chinês -, há, ainda, a dificuldade adicional imposta pelos registros chineses reportados pelo Ministério do Comércio (MOFCOM, na sigla em inglês) e pela State Administration for Foreign Exchange (Safe), que levam em conta somente os projetos aprovados pelo governo. Vale dizer que esses registros podem não 
incorporar os recursos que efetivamente saíram do país e/ou que aportaram em outras economias a partir de empresas chinesas com subsidiárias localizadas em Hong Kong ou outras praças financeiras, bem como projetos que não passaram pelo crivo das autoridades. Esses dados oficiais se desdobram como fonte importante para agências multilaterais que organizam e disseminam estatísticas sobre IDE, como a United Nations Conference on Trade and Development (UNCTAD, 2011).

Fontes alternativas têm procurado mapear os anúncios de investimentos chineses - como o fDi Markets (FDI Markets, 2012) - e/ou rastrear o IDE chinês a partir das informações reportadas diretamente pelas empresas, como a Heritage Foundation (2012) . A despeito de eventuais divergências, todas as fontes apontam para um mesmo fenômeno: a forte expansão do IDE chinês a partir de 2005 e, com mais intensidade, depois de 2008. A Tabela 1 mostra, para o período de janeiro de 2005 a junho de 2011, os investimentos realizados por empresas chinesas no exterior. Em comum, todas essas fontes excluem a aquisição de títulos e a realização de empréstimos, vale dizer; seu foco é a aquisição de capital. As fontes também convergem na percepção de que há um movimento de crescimento exponencial do IDE chinês no período analisado, de modo que é razoável assumir que o volume acumulado de inversões exceda os US\$200 bilhões no período 2005 a 2010.

Tabela 1 - Investimentos chineses no exterior, 2005-2011* (em US\$ milhões)

\begin{tabular}{l|c|c|c|c}
\hline & MOFCOM & UNCTAD & fDi & Heritage \\
\hline 2005 & 12.600 & 12.261 & 9.473 & 6.230 \\
\hline 2006 & 21.160 & 21.160 & 16.266 & 13.360 \\
\hline 2007 & 26.510 & 22.469 & 30.515 & 30.770 \\
\hline 2008 & 55.910 & 52.150 & 48.985 & 37.800 \\
\hline 2009 & 56.530 & 56.530 & 28.444 & 75.300 \\
\hline 2010 & 68.810 & 68.000 & 29.693 & 68.200 \\
\hline $2011^{*}$ & \multicolumn{5}{|l}{} & 16.673 & 31.010 \\
\hline Memória & 241.180 & 232.570 & 163.375 & 231.660 \\
\hline $2005-2010$ &
\end{tabular}

Nota: $\left({ }^{*}\right)$ janeiro-junho

Fonte: Elaboraçăo própria com base em MOFCOM (2011), UNCTAD (2011), fDi Markets (2012), Heritage Foundation (2011).

Para avaliar o tipo de direcionamento geográfico dos investimentos chineses, o Gráfico 1 reporta o índice de intensidade regional (IIR) ${ }^{8}$, calculado em analogia aos tradicionais indicadores de intensidade de comércio. Um índice maior do que

\footnotetext{
${ }^{8}$ IIR = Rij/Riw. Onde: Rij representa a participação da região “i” no total dos investimentos originados no "país j”; Riw é a participação da mesma região nos investimentos mundiais.
} 
Gráfico 1 - Índice de intensidade regional dos investimentos chineses, 2005-2011*

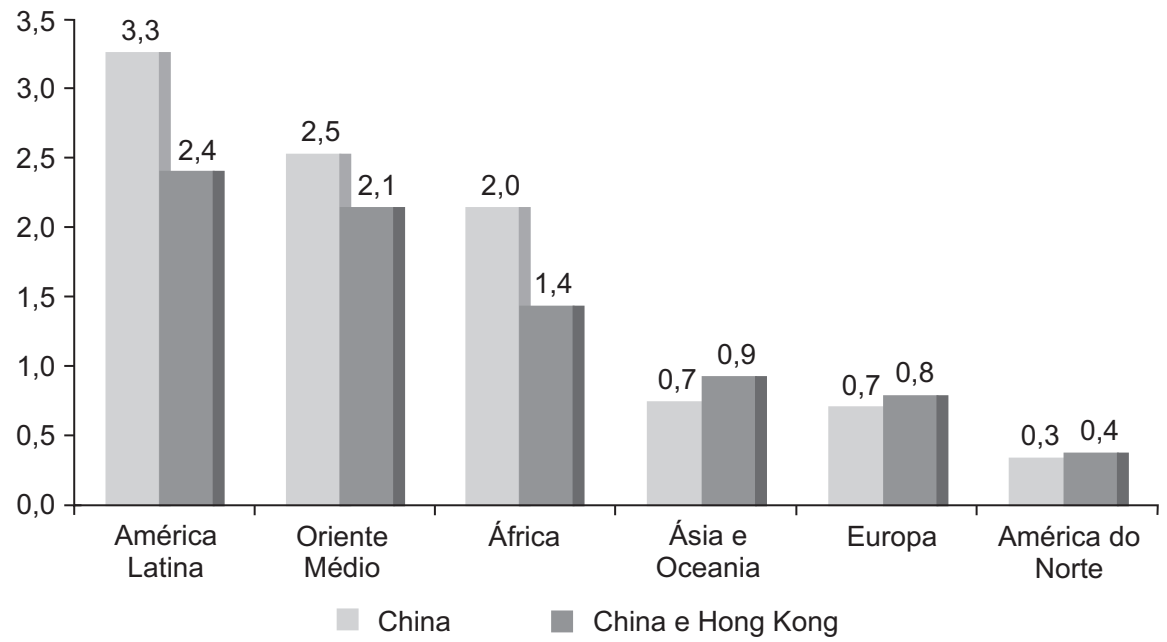

Nota: $\left.{ }^{*}\right)$ até junho.

Fonte: Elaboraçăo própria com base em dados de FDI Markets (2012).

1 indica que aquela região recebe investimentos com maior intensidade relativa, le é mais importante para a economia chinesa do que para o conjunto das economias do mundo. Por esse indicador, o investimento chinês é entre duas e três vezes mais intenso na América Latina, África e no Oriente Médio do que o verificado para o resto do mundo. Foram calculados indicadores para dois agregados: (i) China; e (ii) China mais Hong Kong.

Para o caso da América Latina, a Cepal (2011a, 2011b) aponta para investimentos acumulados da ordem de US\$ 7,3 bilhões no período 1990-2000, de US\$ 15,2 bilhões em 2010, e de US\$22,7 bilhões para o período pós-2011. Tão importante quanto o montante envolvido é perceber sua dinâmica expansiva. Após a crise de 2008, a China busca transformar seu poderio financeiro estatal e corporativo em termos da aquisição de ativos estratégicos, especialmente se provedores de acesso futuro ao suprimento de recursos naturais ou de mercados.

\section{ALGUMAS EVIDÊNCIAS SOBRE CONVERGÊNCIA DE CICLOS E PADRÕES DE COMÉRCIO}

Esta seção busca evidências que corroborem nossa hipótese principal. Assim, apesar das intenções de reorientar o modelo de crescimento para a demanda doméstica, a resposta dos formu ladores de política chineses reforçou, ao menos no curto e médio 
prazos, a dependência do país em exportações e investimentos ${ }^{9}$. Considerando a apática recuperação das economias avançadas, tal estratégia irá ampliar as pressões chinesas para acessar mercados dinâmicos em países emergentes. Neste contexto, o Brasil desponta como um caso especial, pois é, ao mesmo tempo, grande produtor e exportador de recursos naturais e produtor diversificado de manufaturas. Como consequência, o país experimenta tanto os estímulos positivos da demanda chinesa por recursos naturais e alimentos, quanto a concorrência das suas exportações, particularmente para os países da América Latina, principal destino das exportações brasileiras de produtos manufaturados.

Com o objetivo de explicitar a posição brasileira, o Gráfico 2 revela a sincronização dos ciclos de negócios entre o Brasil e os seus principais parceiros comerciais entre 1975 e 2010. A figura sugere que os ciclos do Brasil estão cada vez mais correlacionados com a China e Argentina, e menos correlacionados com os Estados Unidos (painel A). Da mesma forma, há maior sincronização com as economias latino-americanas, à exceção do México (painel B), e asiáticas (painel D). Dentre as economias maduras destacadas, somente com o Japão e, em com menor intensidade, a Alemanha, vislumbra-se esse maior entrelaçamento (painel C). Tal sincronização pode ser explicada pelo comércio e está associada a um padrão de negócios em que o Brasil tende a especializar-se na produção e exportação de recursos naturais. Calderón (2008) encontrou resultados semelhantes ao estudar a convergência cíclica entre os países da América Latina, Índia e China. Cesa-Bianchi et al. (2011) mostraram que, devido aos canais de comércio, o impacto de longo prazo de um choque do PIB chinês sobre as economias latino-americanas triplicou desde meados da década de 1990, enquanto que os impactos de longo prazo de um choque do PIB americano diminuíram pela metade. Por sua vez, o Banco Interamericano de Desenvolvimento (IADB, 2012) sugere que as economias latinoamericanas estão cada vez mais vulneráveis às oscilações na economia chinesa.

Para verificar se a sincronização do ciclo de negócios brasileiro com seus principais parceiros comerciais ${ }^{10}$ está associado à intensidade do comércio bilateral, utilizou-se a

\footnotetext{
${ }^{9}$ De acordo com Fenby (2011, p. 36): “The massive government reaction to the government downturn and financial crisis of 2008-2010 saw China emerging from the recession sooner than other economies. But it set back the rebalancing which is needed to diminish reliance in exports and fixed-assets investments as growth drivers".

${ }^{10}$ Além de Brasil e China, o exercício utilizou os seguintes países, distribuídos regionalmente da forma que segue: América do Sul: Argentina, Bolívia, Colômbia, Chile, Equador, Paraguai, Peru, Venezuela e Uruguai; América do Norte: Canadá, Estados Unidos e México; União Europeia: Alemanha, França, Holanda, Itália e Espanha; África: Angola, Argélia, Egito, Nigéria, África do Sul; Oriente Médio: Emirados Árabes Unidos e Arábia Saudita; Ásia: Îndia, Indonésia, Japão, Coreia do Sul, Malásia, Cingapura, Tailândia, Vietnã e Filipinas; Outros: Turquia e Rússia. Todos os dados utilizados são provenientes do Banco Mundial (World Bank, 2012) e FMI (IMF, 2012). Os ciclos foram calculados para o período 1975-2010, com informações do intervalo temporal 1960 a 2010. Os fluxos de comércio utilizam dados do período 1990-2010. As variáveis instrumentais da equação gravitacional foram obtidas da base do CEPII (www.cepii.fr/anglaisgraph/bdd/ gravity.htm). Todos os testes realizados estão disponíveis mediante solicitação aos autores.
} 


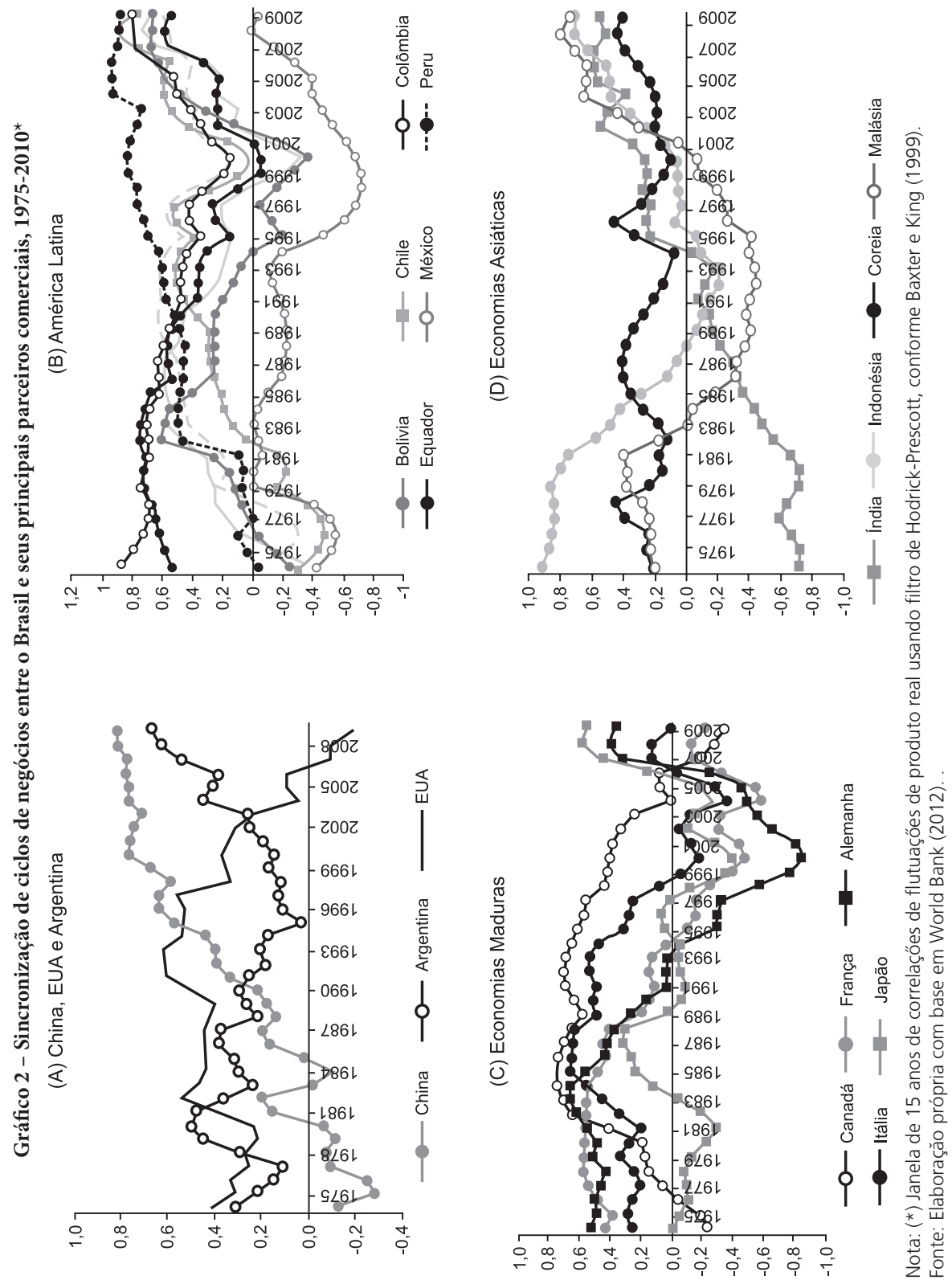


estratégia empírica desenvolvida por Frankel e Rose (1998) e expandida por Calderón (2008), dentre outros. Estimou-se a equação: $\operatorname{Corr}(v, s) i j t=\alpha+\beta$ ITijt $+\varepsilon$ ijt, onde: Corr (v, s)ijt denota a correlação de ciclos econômicos entre o país i e o j, no tempo $t$ para a proxy de atividade econômica, que aqui corresponde ao PIB real. Foram utilizadas duas metodologias alternativas de estimação dos ciclos, de Hodrick-Prescott (HP) e de Baxter e King (BK). IT refere-se à intensidade comercial. Em nossos exercícios, ponderou-se o comércio bilateral pelo total do comércio (ITT) e pelo tamanho das economias (ITY), conforme reportado na tabela 2. Finalmente $\alpha$ e $\beta$ são os coeficientes da regressão a serem estimados. Foram estimadas oito versões diferentes do modelo, derivados das duas definições de ciclos, dos dois países de referência e das duas medidas de intensidade comercial. A Tabela 1 mostra os resultados: $\beta$ foi estaticamente significativo em todas as estimativas. De acordo com a literatura, um $\beta$ positivo sugere que uma maior intensidade de comércio reforça a sincronização de ciclos de comércio ${ }^{11}$.

Com base nos resultados da Tabela 2, pode-se argumentar que, no caso brasileiro, convergência entre os ciclos de negócios está associada à intensidade do comércio bilateral. Vale também mencionar que todas as estimativas feitas resultaram em um $\beta$ negativo para o caso chinês, o que significa que o comércio intraindústria prevalece entre a China e seus parceiros. Dessa forma, o comércio não contribuiria para a sincronização de ciclos de negócios. Ele pode estar contribuindo para o crescimento econômico chinês, entretanto o país parece estar sendo capaz de isolar os efeitos dos ciclos internacionais de negócios na sua dinâmica de crescimento.

A estratégia chinesa de diversificação de exportações pode ser visualizada, em termos dos mercados de destino, na Tabela 3, que mostra o índice de razão de

Tabela 2 - Efeitos da intensidade de comércio na sincronização de ciclos de negócios, Brasil e China, 1975-2010

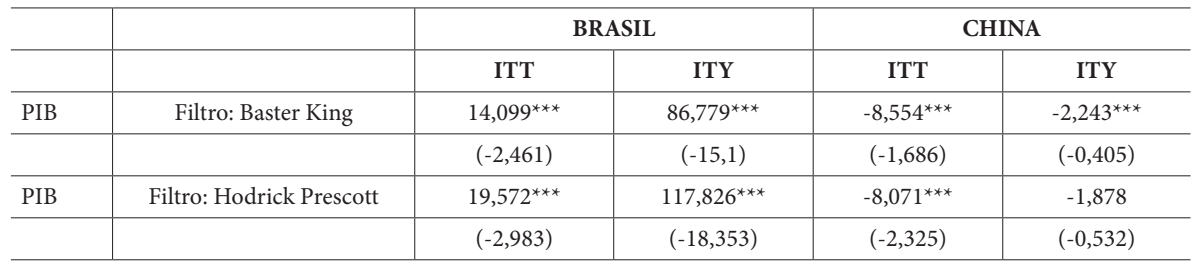

Notas: $\left.{ }^{*}\right) p<0,05 ;\left(^{* *} p<0,01 ;\left(^{* * *} p<0,001\right.\right.$. Para estimar a equaçăo utilizou-se IT (intensidade comercial) como variável instrumental (IV), de modo a resolver o problema de homegeneidade entre comércio e PIB. A variável instrumental foi estimada por meio de um modelo gravitacional tradicional, com os controles usuais para idioma, fronteira e distância. A equaçăo foi estimada por meio de dados de painel. O texto de Hausman revelou que o 2SLS (Two-Stages Least Squares) é eficiente e o teste de Sargan validou os instrumentos.

Fonte: Elaboraçăo própria com base em World Bank (2012) e IMF (2012).

\footnotetext{
${ }^{11}$ Detalhes metodológicos em Frankel e Rose (1998) e Calderón (2008).
} 
Tabela 3 - Índice de razão de concentração das exportações chinesas* 1995, 1999, 2004, 2008 e 2010

\begin{tabular}{|c|c|c|c|c|c|}
\hline \multicolumn{6}{|c|}{ China no mundo } \\
\hline & 1995 & 1999 & 2004 & 2008 & 2010 \\
\hline $\mathrm{CR}(1)$ & $19,13 \%$ & $21,53 \%$ & $21,05 \%$ & $17,66 \%$ & $17,94 \%$ \\
\hline $\mathrm{CR}(2)$ & $35,74 \%$ & $38,14 \%$ & $33,44 \%$ & $25,79 \%$ & $25,56 \%$ \\
\hline $\mathrm{CR}(3)$ & $40,24 \%$ & $42,14 \%$ & $38,12 \%$ & $30,96 \%$ & $29,92 \%$ \\
\hline $\mathrm{CR}(4)$ & $44,05 \%$ & $46,13 \%$ & $42,12 \%$ & $35,10 \%$ & $34,23 \%$ \\
\hline $\mathrm{CR}(5)$ & $46,40 \%$ & $48,90 \%$ & $45,24 \%$ & $38,32 \%$ & $37,38 \%$ \\
\hline $\mathrm{CR}(10)$ & $55,17 \%$ & $58,78 \%$ & $55,41 \%$ & $49,48 \%$ & $48,33 \%$ \\
\hline $\mathrm{CR}(15)$ & $60,55 \%$ & $64,18 \%$ & $62,32 \%$ & $57,66 \%$ & $56,74 \%$ \\
\hline \multicolumn{6}{|c|}{ Principais destinos - posição } \\
\hline Estados Unidos & 2 & 1 & 1 & 1 & 1 \\
\hline Japão & 1 & 2 & 2 & 2 & 2 \\
\hline Coreia do Sul & 3 & 3 & 3 & 3 & 3 \\
\hline Alemanha & 4 & 4 & 4 & 4 & 4 \\
\hline Países Baixos & 6 & 5 & 5 & 5 & 5 \\
\hline Índia & 23 & 21 & 17 & 9 & 6 \\
\hline Reino Unido & 8 & 6 & 6 & 6 & 7 \\
\hline Cingapura & 5 & 7 & 8 & 8 & 8 \\
\hline Itália & 9 & 10 & 10 & 10 & 9 \\
\hline Taiwan & 7 & 8 & 7 & 11 & 10 \\
\hline Rússia & 12 & 17 & 11 & 7 & 11 \\
\hline França & 10 & 9 & 9 & 13 & 12 \\
\hline Austrália & 13 & 11 & 12 & 14 & 13 \\
\hline Brasil & 24 & 25 & 24 & 18 & 14 \\
\hline Malásia & 16 & 16 & 14 & 16 & 15 \\
\hline
\end{tabular}

Nota: $\left.{ }^{*}\right)$ Exclui Hong Kong.

Fonte: Elaboraçăo própria com base em GTIS (2012).

concentração $(\mathrm{CR})$, caracterizando qual a parcela que as "n" regiões têm no total exportado pela economia chinesa. Assim, o valor encontrado para o CR(1) apresenta a parcela das exportações da China dirigidas ao seu principal parceiro, já o CR(2) caracteriza esse mesmo indicador para os dois principais parceiros, e assim sucessivamente.

Nota-se a desconcentração de destinos da pauta exportadora da China, particularmente no CR(15), bem como a importância crescente dos parceiros regionais e dos grandes mercados emergentes, dentre os quais o Brasil. Esse processo tem sido reforçado pela diversificação em termos de produtos exportados. O Gráfico 3 introduz o 
índice de concentração setorial ${ }^{12}$ das exportações (Herfindahl-Hirschman, HHI), que obedece à seguinte definição:

$$
H H I_{j}=\sum_{k=1}^{n}\left(\frac{x_{j, k}}{X_{j, w}} \times 100\right)^{2}
$$

Onde:

$x_{j, k}=$ Exportações do setor " $\mathrm{k}$ ” realizadas pelo país “j”

$X_{j, w}=$ Exportações totais originadas no país “j”

Esse indicador apresenta uma escala onde um resultado menor do que 1000 indica baixa concentração, um HHI entre 1000 e 1800 caracteriza concentração moderada, e, por fim, um valor de HHI superior a 1800 indica uma situação onde a pauta exportadora está concentrada em poucos setores.

De um modo geral, observa-se baixa concentração (ou alta desconcentração) da pauta chinesa em todos os mercados de destino. Todavia, o período pós-crise marca um movimento de leve concentração nos mercados maduros e de desconcentração nas

Gráfico 3 - Índice Herfindahl-Hirschman (HHI) de concentração setorial da pauta de exportações da China, 1994 a 2010

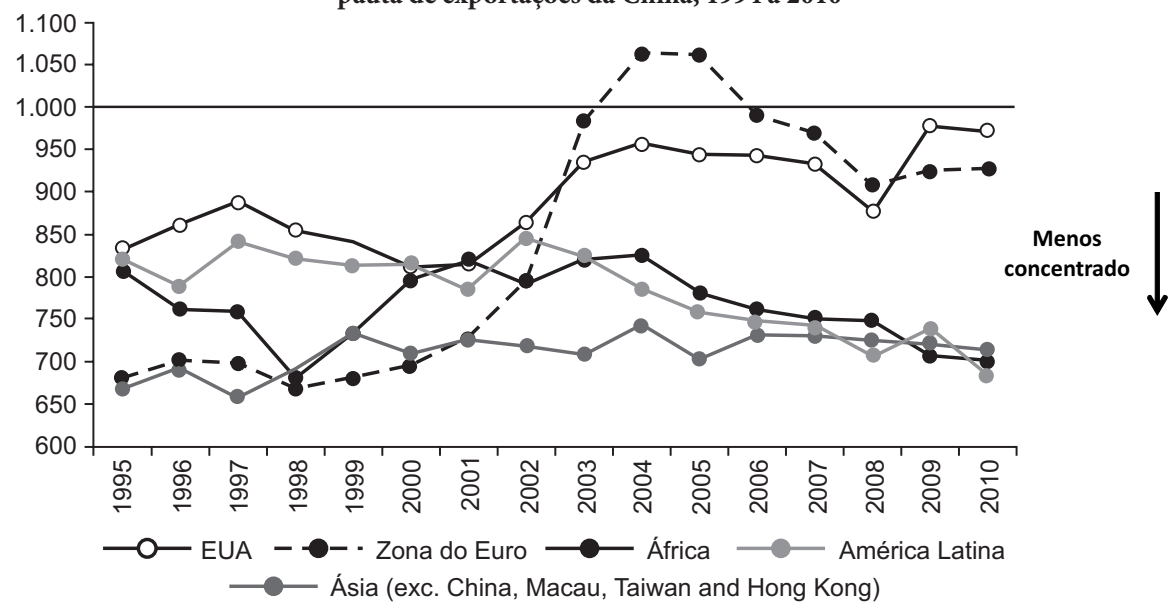

Fonte: Elaboraçăo própria com base em UN COMTRADE (2012).

\footnotetext{
${ }^{12} \mathrm{O}$ indicador foi calculado tomando por base os setores delimitados pela Classificação Nacional de Atividades Econômicas (CNAE v ersão 1.0), com detalhamento de dois dígitos. A CNAE foi elaborada nos anos 1990 pelo IBGE em conjunto com os órgãos de registro administrativo, com o objetivo de alcançar uma padronização das informações econômicas do Brasil. A construção da CNAE tomou como referência a classificação padrão elaborada pela Divisão de Estatísticas das Nações Unidas, a International Standard Industrial Classification of All Economic Activities (ISIC).
} 
demais regiões. Ainda assim, constata-se que o HHI é menor do que 1000, em 2010, para todas as regiões.

A Tabela 4 mostra a composição das exportações e das importações da China, respeitando a agregação por padrão tecnológico de Pavitt ${ }^{13}$.

Há um processo significativo de diminuição dos produtos intensivos em trabalho nas exportações da China no período em foco. Ao mesmo tempo tem-se uma elevação dos manufaturados produzidos por fornecedores especializados, intensivos em escala e intensivos em pesquisa e desenvolvimento (P\&D). Os setores apontados como manufaturas produzidas por fornecedores especializados são aqueles associados aos bens de capital sob encomenda. Com respeito aos bens intensivos em escala, têm-se as indústrias automobilística, siderúrgica e os bens de eletrônicos de consumo (principalmente, vídeo, áudio e a linha branca). Para as exportações chinesas, predominam os setores de fabricação de aparelhos receptores de rádio e televisão e de reprodução, gravação ou amplificação de som e vídeo, e o de fabricação de eletrodomésticos. Já os setores que compõem os produtos intensivos em P\&D são a química fina, os componentes eletrônicos, a telecomunicação e a indústria aeroespacial. Em relação às vendas externas da China, o setor de fabricação de aparelhos e equipamentos de telefonia e radiotelefonia e de transmissores de televisão e rádio apresenta a maior participação. Percebe-se, então, mais uma qualidade do movimento chinês no interior do comércio exterior global, isto é, agregar valor a pauta dos produtos exportáveis em um período relativamente curto. Por sua vez, aumentou o peso relativo dos produtos primários e manufaturados intensivos em recursos naturais na pauta importadora.

Tabela 4 - Exportações e importações chinesas por intensidade tecnológica, 1995 e 2010

\begin{tabular}{l|c|c|c|c}
\hline Tipologia & \multicolumn{2}{|c|}{ Exportações } & \multicolumn{2}{c}{ Importaç̃̃es } \\
\hline Produtos primários & $\mathbf{1 9 9 5}$ & $\mathbf{2 0 1 0}$ & $\mathbf{1 9 9 5}$ & $\mathbf{2 0 1 0}$ \\
\hline Produtos intensivos em recursos naturais & $8,23 \%$ & $2,31 \%$ & $8,50 \%$ & $24,02 \%$ \\
\hline Manuf. intensivos em trabalho & $11,40 \%$ & $7,95 \%$ & $18,20 \%$ & $14,66 \%$ \\
\hline Manuf. intensivos em economias de escala & $45,59 \%$ & $27,67 \%$ & $20,00 \%$ & $8,69 \%$ \\
\hline Manuf. produzidos por fornecedores especializados & $15,62 \%$ & $20,04 \%$ & $10,43 \%$ & $9,68 \%$ \\
\hline Manuf. intensivos em P\&D & $7,33 \%$ & $23,98 \%$ & $23,95 \%$ & $16,82 \%$ \\
\hline Não classificados & $5,90 \%$ & $17,94 \%$ & $11,24 \%$ & $24,81 \%$ \\
\hline Total & $5,93 \%$ & $0,10 \%$ & $7,68 \%$ & $1,32 \%$ \\
\hline
\end{tabular}

Nota: Classificaçăo setorial baseada em Pavitt (1984).

Fonte: Elaboraçăo própria com base em GTIS (2012).

\footnotetext{
${ }^{13}$ A tipologia utilizada na caracterização dos padrões tecnológicos foi desenvolvida por Pavitt (1984) e ampliada por Holland e Xavier (2005).
} 


\section{BRASIL E AMÉRICA LATINA NO ESPELHO DA CHINA}

Já há uma volumosa literatura que procura avaliar os impactos da ascensão chinesa na América Latina. Lederman et al. (2008), Jenkins (2010), CEPAL (2011a, 2011b), Phillips (2011), e Leão et al. (2011) oferecem uma revisão atualizada dos argumentos, onde se percebe uma clara clivagem entre otimistas e pessimistas. No primeiro campo, identifica-se na demanda chinesa por recursos naturais uma fonte de dinamismo para as economias da região e, nas importações de produtos finais e equipamentos, o potencial para aumento no bem-estar e na competitividade dos produtores locais. Ademais, o estabelecimento de parcerias com empresas chinesas e o investimento direto originado no gigante asiático contribuiriam, respectivamente, para que empresas latino-americanas possam ampliar sua internacionalização como partes constituintes de redes globais de produção e para o financiamento do balanço de pagamentos e de obras de infraestrutura. No outro campo, mesmo admitindo o potencial benefício da demanda chinesa, os pessimistas enfatizam os riscos associados à excessiva especialização na produção e exportações de produtos intensivos em recursos naturais, em meio a um processo de renovado ímpeto desindustrializante, particularmente nas economias mais diversificadas. Assumindo-se que há efeitos distintos entre economias ricas e exportadoras de recursos naturais, especialmente na América do Sul, e economias mais vinculadas ao mercado estadunidense e exportadoras de manufaturas intensivas em trabalho, como México, América Central e Caribe, verifica-se que o deslocamento das exportações de manufaturas, o desvio de IDE da região para a China e o retorno a uma situação dependente e reflexa remeteriam a um quadro de especialização regressiva, equivalente àquele criticado pela economia política cepalina (Prebisch, 1984; Furtado, 2003).

Nesses marcos, a situação brasileira sugere a ocorrência dos dois efeitos, isto é, o estímulo aos setores que se beneficiam da demanda chinesa por recursos naturais e a pressão competitiva na indústria. O Gráfico 4 ilustra essa situação: enquanto a indústria de transformação teve um incremento em seu déficit externo entre 2008 e 2011, o setor primário obteve superávits expressivos.

Mesmo que as evidências aqui reunidas não permitam afirmar que tal comportamento se deve aos laços comerciais entre Brasil e China, não se pode desconsiderar esta possibilidade. A literatura internacional tem apontado para evidências neste sentido, onde a concorrência com as exportações chinesas deslocam seus rivais dos principais mercados e agravam a perda de dinamismo na produção industrial ${ }^{14}$. A preocupação com a desindustrialização emerge do fato de que, desde o seu ápice, na

\footnotetext{
${ }^{14}$ Ver Greenway et al. (2008), Giovannetti e Sanfilippo (2009), Wood e Mayer (2010), e Lélis et al. (2012).
} 
Gráfico 4 - Balança comercial do Brasil em setores selecionados, 1989-2011 (em US\$ bilhões)

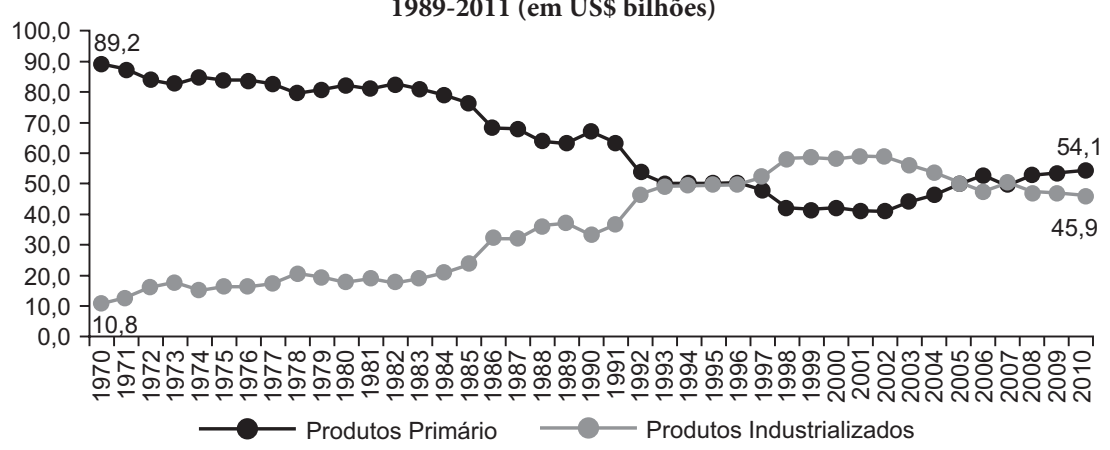

Fonte: IEDI $(2012,2011)$.

década de 1980, o setor manufatureiro tem reduzido sua participação no PIB $^{15}$ (de 33\%, em 1980, para 16\% em 2010) e no emprego total. Bresser-Pereira (2010) e Palma (2011, 2007) sugerem que as economias latino-americanas sofrem com uma dinâmica de desindustrialização precoce, visível quando se controla essa tendência para os níveis de renda per capita. $\mathrm{O}$ excesso de dependência dos setores intensivos em recursos naturais e a ausência de políticas desenvolvimentistas, em claro contraste com a experiência asiática, são apontados como explicações plausíveis para o desempenho medíocre dos países da região.

Cabe lembrar que, em 1980, o Brasil tinha o maior setor manufatureiro entre os países em desenvolvimento, figurando na oitava posição global, com 2,6\% do valor adicionado internacionalmente. Naquele ano, a China estava na décima segunda posição, com $1,7 \%$, e a Coreia do Sul na vigésima sétima posição, com $0,6 \%$ da produção mundial de produtos manufaturados. Em 2010, o Brasil aparecia em décimo primeiro lugar, atrás da China, Coreia do Sul, Índia e do México ${ }^{16}$. Entretanto, apesar de seu declínio relativo, o Brasil ainda contribui com $1,7 \%$ da produção global.

Do ponto de vista do comércio internacional, enquanto a China passou de uma participação equivalente à brasileira nas exportações de mercadorias no começo dos anos 1980 , em cerca de $1,5 \%$ do total mundial para mais de $10 \%$ depois de 2010 , o Brasil recuou para menos de $1 \%$ nos anos 1990, retomando aquele patamar somente no final da primeira década do século XXI. Em uma perspectiva mais ampla, a participação da América Latina tem oscilado por volta de $7 \%$ nas últimas quatro décadas, período de forte ascensão asiática. Tal quadro agrava-se na medida em que a pauta exportadora voltou a se concentrar em produtos primários, para o conjunto da região, conforme pode ser observado no Gráfico 5.

\footnotetext{
15 Todos em preços de dólares atuais (United Nations, 2012).

${ }^{16}$ Ver United Nations (2012), Palma (2011, 2007).
} 
O comércio com os países do Leste Asiático é particularmente intensivo nas exportações de recursos naturais (gráfico 6). Países como o Brasil e México têm tido nos mercados regionais, nos EUA e em países de renda média os principais destinos para suas exportações de manufaturas. É exatamente nestes mercados que a concorrência chinesa tem se intensificado, particularmente no período pós-crise financeira global ${ }^{17}$ (Lélis et al., 2012; Jenkins e Barbosa, 2012).

Gráfico 5 - Estrutura das exportações da América Latina, 1970-2010 (em \%)

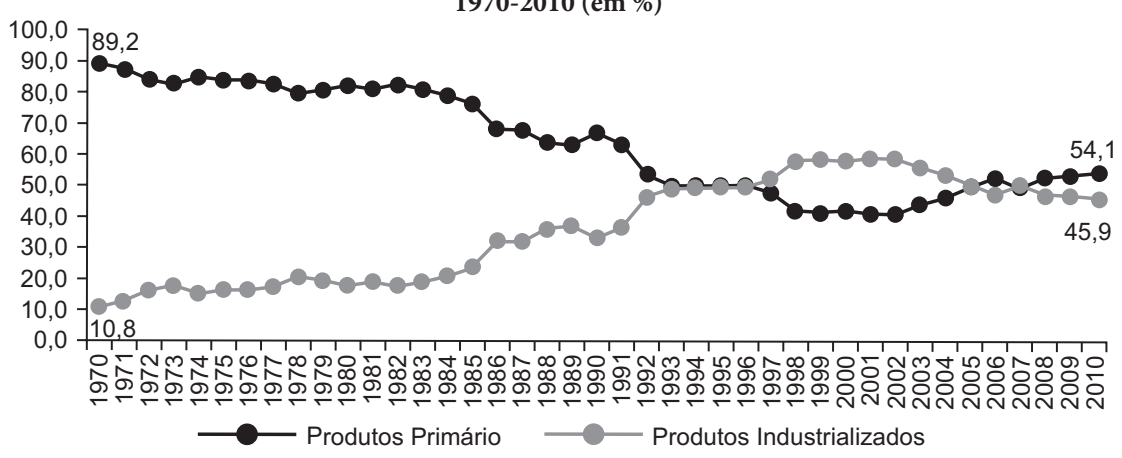

Fonte: CEPAL (2012).

Gráfico 6 - Estrutura de exportações da América Latina por destinos principais, 2008-2010 (média, em \%)

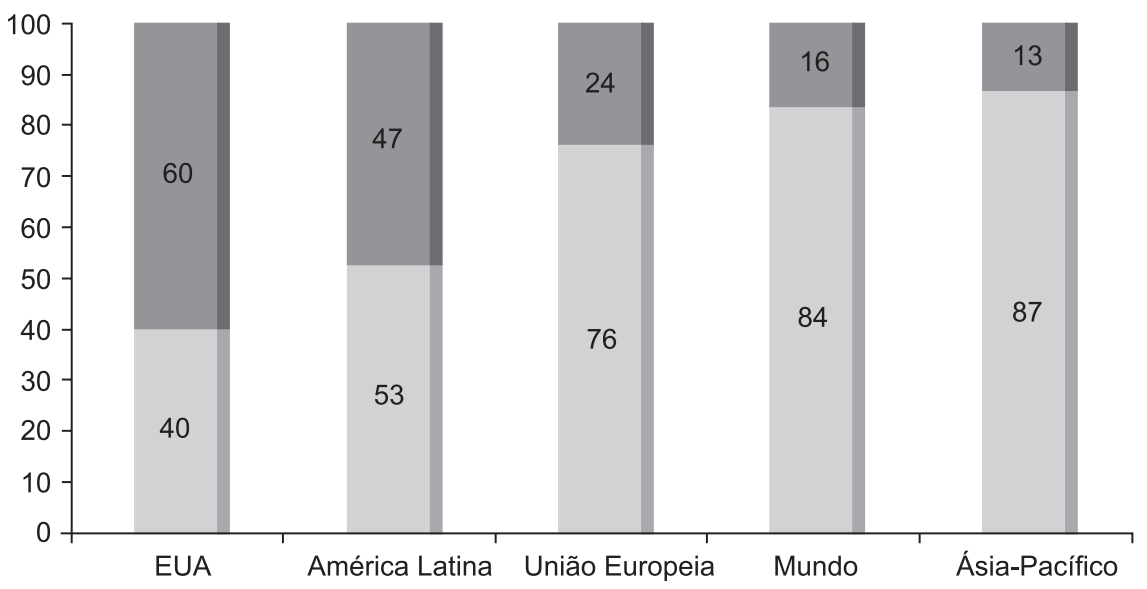

Recursos Naturais e Manufaturas Intensivas em RN Outras Manufaturas Fonte: CEPAL (2011b)

\footnotetext{
${ }^{17}$ Evidências para o período pré-CFG estão amplamente documentadas em Bittencourt (2012).
} 
É bem verdade que este quadro mais geral precisa ser matizado, na medida em que várias economias da região são estruturalmente dependentes da produção e exportação de commodities, casos de Argentina, Chile, Colômbia e Venezuela, dentre outros (Gráfico 7, Painel A). Já México e Brasil (Gráfico 7, Painel B), que conseguiram, ao longo de seu esforço industrializante, diversificar suas estruturas de produção e exportação, experimentaram no ciclo recente de alta dos preços das commodities, em parte devido à demanda chinesa, uma tendência de aumento na participação relativa dos produtos intensivos em recursos naturais. Segundo a Cepal (2011a, 2011b), nos dois conjuntos

Gráfico 7 - Exportações de produtos primários em economias selecionadas, 1970-2010 (em \% do total exportado)

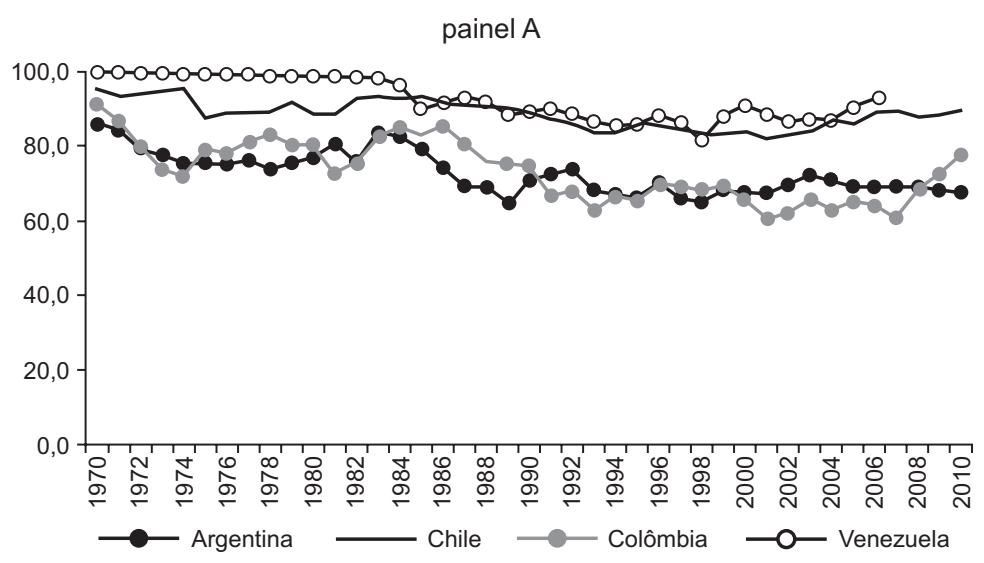

painel B

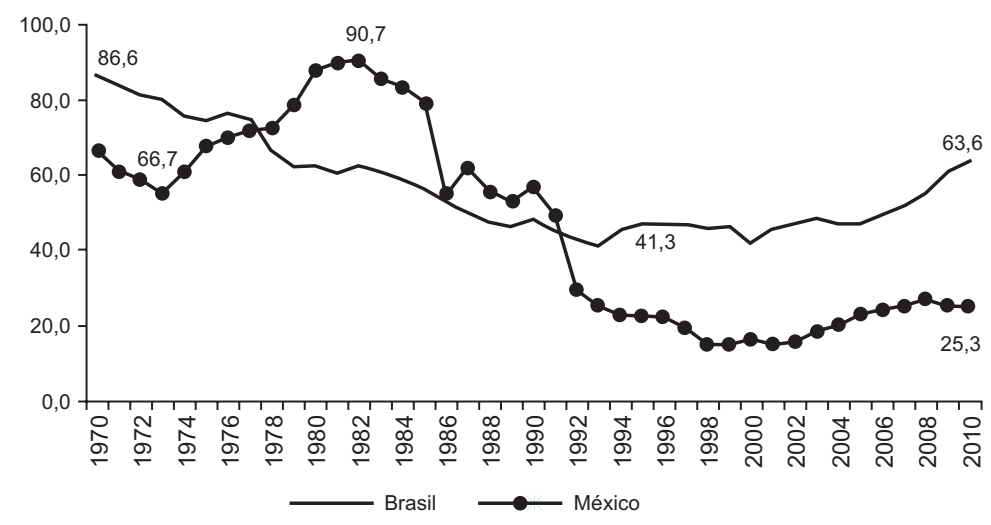


de economias, verifica-se por força da maior vinculação comercial com a China e em função dos impactos da ascensão desta sobre a economia mundial uma especialização em poucos produtos, usualmente recursos naturais não processados (Tabela 5).

Assim, a Tabela 5 reforça a percepção da deterioração na qualidade do comércio bilateral, onde a China passa a comprar produtos com o menor grau de processamento possível e a exportar manufaturas cada vez mais sofisticadas, reproduzindo o quadro clássico de comércio Norte-Sul criticado por Prebisch (1984) e Furtado (2003).

Por sua vez, a Tabela 6 e o Gráfico 8 sugerem o espelho brasileiro da realidade chinesa, onde o perfil de exportações nacionais experimenta uma regressão qualitativa, dada: (i) a queda na participação dos produtos manufaturados intensivos em trabalho e escala no total exportado; e (ii) a concentração da pauta de produtos nos diversos mercados de destinos. É importante lembrar as evidências da seção 3: a China trilha o caminho oposto, agregando tecnologia e valor à pauta exportadora e diversificando mercados de destinos e os produtos exportados.

Considerando a relevância do comércio intrarregional para o Brasil e as evidências da literatura internacional (Greenway et al., 2008; Giovannetti e Sanfilippo, 2009; Wood e Mayer, 2010), é importante ponderar se a China vem substituindo o Brasil no mer-

Tabela 5 - Estrutura do Comércio Bilateral entre América Latina (excl. México) e China, 1990-2008 (\%)

\begin{tabular}{l|rr|rr}
\hline & \multicolumn{2}{|c|}{ Exportações } & \multicolumn{3}{|c}{ Importações } \\
\hline Produtos Primários & $\mathbf{1 9 9 0}$ & $\mathbf{2 0 0 8}$ & \multicolumn{1}{c}{$\mathbf{1 9 9 0}$} & $\mathbf{2 0 0 8}$ \\
Produtos Manufaturados Intensivos em Recursos Naturais e Trabalho & $\mathbf{2 9 , 2}$ & $\mathbf{7 2 , 1}$ & 42,8 & 2,4 \\
Outros Manufaturados & 17,5 & 6,8 & 25,2 & 22,9 \\
Total & 53,3 & 21,0 & $\mathbf{3 1 , 9}$ & $\mathbf{7 4 , 7}$ \\
\hline
\end{tabular}

Fonte: CEPAL (2011b)

Tabela 6 - Exportações e Importações Brasileiras por Intensidade Tecnológica, 1997-2010*

\begin{tabular}{|c|c|c|c|c|c|c|}
\hline & \multicolumn{4}{|c|}{ Exportações } & \multicolumn{2}{|c|}{ Importações } \\
\hline & 1997 & & 2010 & & 1997 & 2010 \\
\hline Produtos Primários & $22,5 \%$ & \multirow{2}{*}{\} $51,8 \%$} & $42,6 \%$ & \multirow{2}{*}{\} $66,5 \% \uparrow$} & $13,5 \%$ & $14,0 \%$ \\
\hline Produtos Intensivos em Recursos Naturais & $29,3 \%$ & & $23,9 \%$ & & $19,9 \%$ & $20,6 \%$ \\
\hline Manuf. Intensivos em Trabalho & $10,6 \%$ & \multirow{2}{*}{$32,6 \%$} & $5,7 \%$ & \multirow{2}{*}{\} $19,8 \% \downarrow$} & $10,3 \%$ & $9,2 \%$ \\
\hline Manuf. Intensivos em Economias de Escala & $22,0 \%$ & & $14,1 \%$ & & $17,9 \%$ & $20,1 \%$ \\
\hline $\begin{array}{l}\text { Manuf. Produzidos por Fornecedores } \\
\text { Especializados }\end{array}$ & $9,7 \%$ & & $7,0 \%$ & & $21,8 \%$ & $19,6 \%$ \\
\hline Manuf. Intensivos em P\&D & $4,4 \%$ & & $4,9 \%$ & & $16,6 \%$ & $16,4 \%$ \\
\hline Não-Classificados & $1,5 \%$ & & $1,9 \%$ & & $0,0 \%$ & $0,0 \%$ \\
\hline Total & $100,0 \%$ & & $100,0 \%$ & & $100,0 \%$ & $100,0 \%$ \\
\hline
\end{tabular}

(*) Taxonomia inspirada em Pavitt (1984).

Fonte: Elaboraçăo própria com base em GTIS (2012). Nota 


\section{Gráfico 8 - Concentração das exportações brasileiras,} 1995-2010 (Herfindhal-Hirschman)

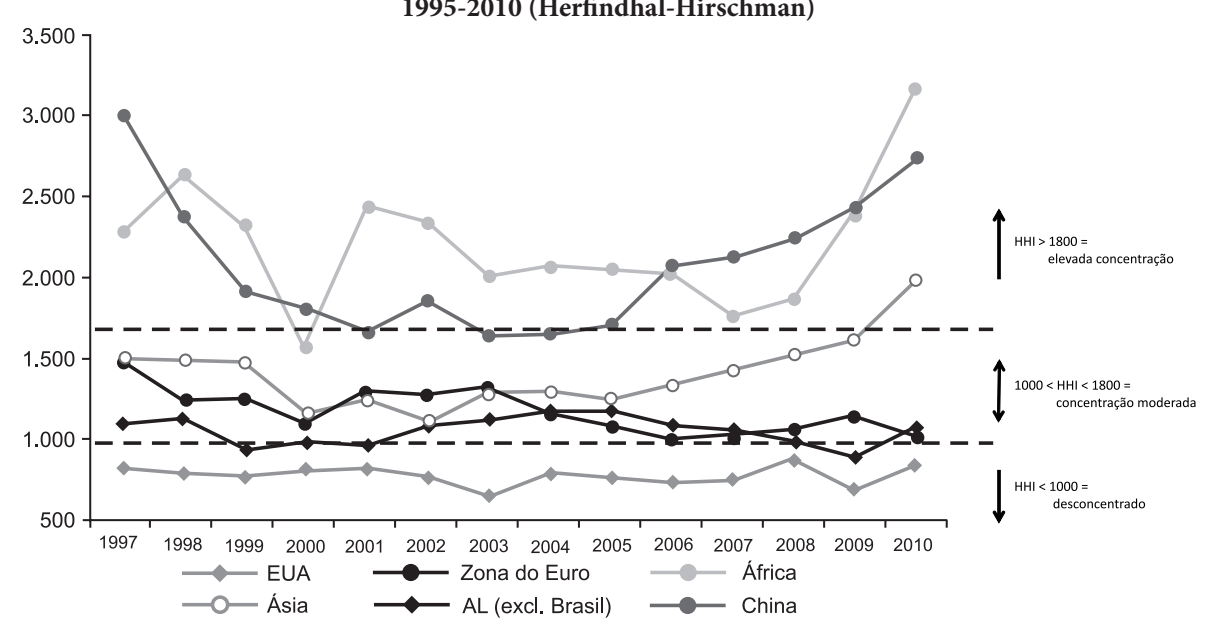

Fonte: Elaboraçăo própria com base em GTIS (2012).

cado latino-americano de produtos manufaturados. De acordo com Lélis et al. (2012), Bittencourt (2012) e Jenkins e Barbosa (2012), dentre outros, a resposta provável é que sim. Lélis, Cunha e Lima (op.cit.) sugerem que, entre 1994 e 2008, particularmente no período pós-2003, as exportações tanto chinesas quanto brasileiras de manufaturas para a região tiveram grande crescimento. A recuperação econômica latino-americana pós-2002 abriu espaço para tal expansão. Entretanto, as exportações chinesas cresceram 40 vezes mais que as do Brasil. Naturalmente, as exportações chinesas eram muito inferiores às brasileiras há alguns anos; agora, isso não é mais verdade. Desde 2007, a exportação de produtos manufaturados chineses vem crescendo mais rápido do que a exportação de produtos manufaturados brasileiros.

Lélis et al. (op.cit.) mostram que as exportações chinesas para a América Latina são menos concentradas que as exportações brasileiras para a região ${ }^{18}$, enquanto as exportações chinesas corresponderam às importações da América Latina mais que as exportações brasileiras. Em 1996, o índice de comércio complementar ${ }^{19}$ das exportações chinesas para a América Latina (excluindo o Brasil) era de 47,6, enquanto que,

\footnotetext{
${ }^{18}$ Índice de concentração de exportações (Herfindhal-Hirschman) de exportações brasileiras flutuou em torno de 1000, entre 1996 e 2008, e alcançou 1007 em 2008, enquanto que o mesmo índice para as exportações chinesas evoluiu de 895, em 1996, para 685 em 2008 (Lélis, Cunha e Lima, 2012).

${ }^{19} \mathrm{TCij}=100$ - sum (|mik - xij| / 2), onde: (i) xij é a participação do bem "i" no total de exportações do país “j”; e (ii) "mik" é a participação do bem “i” no total de importações do país k. Quando o índice é zero, nenhum bem é exportado pelo país ou importado pelo outro. Quando o índice é 100, as quantidades importadas e exportadas correspondem (Hoekman et al., 2002).
} 
em 2008, cresceu para 58,9. No mesmo período, o índice de comércio complementar das exportações brasileiras foi, respectivamente, 56,9 e 50,8. Para os autores, as exportações chinesas vêm substituindo as brasileiras na região devido ao seu efeito-volume e à sua diversificação. Bittencourt (2012) e Jenkins e Barbosa (2012) notam o mesmo fenômeno ao estudar o comportamento das exportações brasileiras e chinesas em diversos mercados, tanto nas economias maduras, quanto nas emergentes.

\section{CONSIDERAÇÕES FINAIS}

A ascensão da China vem afetando, cada vez mais, o desempenho das economias latinoamericanas. A demanda chinesa por produtos agrícolas, minerais e energia resultou, por um lado, em superávits de comércio para países ricos em recursos naturais, o que contribui para um virtuoso ciclo de crescimento com menores vulnerabilidades externas e fiscais (CEPAL, 2011a, 2011b; Rosales e Kuwayama, 2012; IADB, 2012). Países já caracterizados por um alto grau de especialização na produção e exportação de commodities têm reforçado seu padrão de integração internacional, como é o caso da Argentina, do Chile, Peru, da Colômbia e Venezuela, para citar apenas alguns. Por outro lado, países com indústrias de transformação mais robustas e diversificadas, como é o caso do Brasil, têm concentrado as suas exportações em commodities. Há sinais de perda de dinamismo nas exportações de produtos manufaturados e intensificação do processo de desindustrialização (Bresser-Pereira, 2010; Palma, 2011, 2007; Bittencourt, 2012).

As evidências reunidas neste trabalho, bem como a literatura utilizada, permitem concluir que, especialmente no período que se seguiu à crise financeira global, as economias latino-americanas tornaram-se mais vinculadas à economia chinesa, em função dos estreitos canais de comércio. Certamente este é o caso do Brasil. A seção 3 indica que a convergência cíclica observada, nos termos da metodologia empregada, está associada ao aumento nos fluxos de comércio. As economias asiáticas em geral, e a China em particular, ganham espaço como destino das exportações brasileiras, em um movimento que redunda em maior interdependência, por parte do Brasil, para com a dinâmica de expansão da renda daqueles países.

Há, também, clara indicação de especialização regressiva no Brasil. Esse fenômeno tem sido explicado pela literatura aqui utilizada ${ }^{20}$ como sendo o resultado da convergência de, pelo menos, três conjuntos de determinantes: (i) em sua dimensão produtiva, consta-se, desde meados dos anos 1980, perda de dinamismo da indústria de transformação, cujos níveis de investimento, expansão da produção e ganhos de produtividade

\footnotetext{
${ }^{20}$ Ver Bresser-Pereira (2010), IEDI $(2012,2011)$ e Palma (2011, 2007), dentre outros.
} 
têm-se revelado insuficientes para garantir ganhos expressivos de mercado - externo e no embate com importações de outras economias emergentes e maduras; (ii) na dimensão macroeconômica, verifica-se a persistência das distorções dos preços-chave da economia, especialmente taxa de câmbio, taxas de juros e carga tributária, que não contribuem para o estabelecimento de um horizonte mais estável de rentabilidade para o setor privado, particularmente na indústria; e (iii) do ponto de vista estrutural, os baixos níveis de acumulação de capital físico e humano provocam importante restrição para a sustentação de ciclos longos de crescimento da renda, com manutenção de um quadro de relativa estabilidade de preços e do balanço de pagamentos.

Neste sentido, o presente trabalho contribui com evidências adicionais que reforçam aquelas explicações, na medida em que constata que o posicionamento do Brasil, em uma ordem internacional em mutação, parece refletir a ascensão asiática, especialmente da China, por meio da alteração no padrão brasileiro de comércio internacional, agora mais dependente das exportações de recursos naturais e com sinais de perda de capacidade de competir nos mercados local e global (seção 4). Todavia, não se explorou plenamente tais vínculos, o que abre perspectivas para novos estudos visando o esclarecimento do efeito da concorrência chinesa na perda de mercados externos e de dinamismo na produção industrial doméstica, a exemplo de Greenway et al. (2008), Giovannetti e Sanfilippo (2009), Wood e Mayer (2010), Bittencourt (2012), Lélis et al. (2012), Jenkins e Barbosa (2012), dentre outros.

Adicionalmente, afirmou-se que, para sustentar sua trajetória de expansão - tão ou mais importante do ponto de vista de suas lideranças políticas -, a coesão social e o status quo, a China precisa reorientar seu modelo de crescimento, enfatizando a demanda doméstica (seção 2). Esse objetivo está expresso no mais recente plano quinquenal. Todavia, detectou-se um problema de ajuste temporal: no horizonte curto, a China precisa manter o drive exportador e, dada a fragilidade das economias maduras, deve intensificar a penetração nos mercados de economia emergentes. A literatura aqui revisada e nossas próprias evidências sugerem que tal movimento pode ampliar os riscos de deslocamento dos seus concorrentes, como o Brasil, nos mercados de manufaturas, agravando, com isso, os riscos de desindustrialização. Notou-se (seção 3) a diversificação dos mercados de destino e da pauta de exportação da China, bem como sua crescente sofisticação.

O pós-crise também revela uma China mais proativa em sua diplomacia e na busca de internacionalização de seus grupos econômicos. O boom de investimentos chineses no exterior depois de 2008 cria um canal de acesso a fontes de recursos naturais, tecnologias e mercados, necessários para sustentar a estratégia de "ascensão pacífica". Por outro lado, amplia a presença chinesa nos mais diversos países, onde a conexão IDE-exportações pode reforçar a canalização da sua produção industrial para economias com maior potencial de expansão de consumo (Yufan Hao et al., 2009; Nolan, 2011; 
Wong, 2011 ; Salidjanova, 2011). Verificou-se que o IDE chinês é particularmente mais intenso na América Latina, África e no Oriente Médio.

Finalmente, e seguindo os insights do Prof. Antônio Barros de Castro (Castro, 2008; Castro e Castro, 2011), nossos resultados, potencialmente originais em sua ênfase para o período pós-2008, reafirmam que a ascensão chinesa representa um grande desafio para o Brasil, na medida em que o país é grande produtor e exportador de recursos naturais e, também, detentor de robusto e diversificado setor manufatureiro. Consequentemente, o país tem enfrentando ambos os estímulos oriundos do radical deslocamento do eixo dinâmico da economia mundial rumo ao Leste: os positivos, expressos na maior demanda por matérias-primas e alimentos, que abre uma via de crescimento que, em alguma medida, pode se encadear com outras atividades mais sofisticadas ${ }^{21}$; e a negativa, da pressão competitiva chinesa, da desindustrialização com especialização regressiva e dos problemas associados à assim chamada "maldição dos recursos naturais". Para Castro, o Brasil precisa reinventar sua estratégia de desenvolvimento, avançando sobre as políticas contracíclicas adotadas depois de 2008. Para tanto, o Estado tem um papel decisivo, e suas políticas devem potencializar a dimensão positiva dos estímulos oriundos da nova ordem internacional e, na medida do possível, tentar neutralizar os riscos da sua vertente negativa.

Nesses termos, caberia ao Estado brasileiro, dentre outras coisas: (i) reorientar as políticas macroeconômicas para preservar o crescimento da renda e do emprego; (ii) controlar o câmbio e os fluxos de capitais para reduzir os impactos de turbulências externas; (iii) melhorar a distribuição de renda, investir em capital humano e reduzir as diferenças sociais; (iv) implementar políticas de desenvolvimento robustas e sustentáveis visando reduzir gargalos de infraestrutura, aumentar a competitividade da indústria local, elevar os níveis de investimento e, especialmente, preservar o meio ambiente e a biodiversidade do país. Essa é uma agenda ambiciosa, complexa, cuja plena consecução ainda permanece em aberto.

\section{REFERÊNCIAS}

BABONES, S. The middling kingdom - The hype and the reality of China's rise. Foreign Affairs, v. 90, n. 5, Sep./Oct., p. 79-88, 2011.

BAXTER, M.; KING, R. G. Measuring business cycle: approximate band-pass filters form economic time series. The Review of Economics and Statistics, v. 81, n. 4, p. 575-593, 1999.

\footnotetext{
${ }^{21}$ De acordo com Castro, em entrevista concedida no ano de 2010 (Castro e Castro, 2011, p. 156): "O que se quer do etanol, do pré-sal, não se trata de recuperar cadeias produtivas; é mais avançado do que isso, temos que saltar para a frente. Saber as fronteiras estratégicas para criar mercado no Brasil", e "[t]emos que nos tornar fornecedores de automação para o pré-sal, o que vai fecundar as indústrias de equipamentos, aeronáuticas, de material militar, a agricultura de satélites etc."
} 
BIJIAN, Z. China's peaceful rise: speeches of Zheng Bijian 1997-2004. The Brookings Institution, 2005. Disponível em: <http://www.brookings.edu/events/2005/0616china.aspx>. Acesso em: set. 2011.

BIJIAN, Z. The internal and external environments of China's development over the next five years. In: GILL, I.; HUANG, Y.; KHARAS, H. (Eds.) East Asian visions. Washington, DC: The World Bank, 2006.

BITTENCOURT, G. (Coord.) El Impacto de China en América Latina: comercio e inversiones. Montevideo: Red Mercosur de Investigaciones Económicas, 2012.

BRESSER-PEREIRA, L. C. (Ed.) Doença holandesa e indústria. Rio de Janeiro: Editora FGV, 2010.

CALDERÓN, C. Trade, specialization, and cycle synchronization: explaining output comovement between Latin America, China, and India. In: LEDERMAN, D.; OLARREAGA, M.; PERRY, G. (Ed.) China's and India's challenge to Latin America. Washington, DC: The World Bank, 2008.

CASEY, J.; KOLESKI, K. Backgrounder: China's 12th five-year plan. U.S. China Economic \& Security Review Commission, June 24, 2011. Disponível em: <http://www.uscc.gov/ researchpapers/2011/12th-FiveYearPlan_062811.pdf>. Acesso em: out. 2011.

CASTRO, A. B. From semi-stagnation to growth in a sino-centric market. Revista de Economia Política, v. 28, n. 1, Jan./Mar., 2008.

CASTRO, A. C.; CASTRO, L. B. (Orgs.) Antonio Barros de Castro: o inconformista - homenagem do Ipea ao Mestre. Brasília: IPEA, 2011.

CESA-BIANCHI, A.; PESARAN, M. H., REBUCCI, A. XU, T. China's emergence in the world economy and business cycles in Latin America. IDB Working Paper Series, Inter-American Development Bank, n. IDB-WP-266, September, 2011.

CLARK, I. China and the United States: a succession of hegemonies? International aAffairs, v. 87, n. 1, January, p. 13-28, 2011.

COMISSÃO ECONÔMICA PARA A AMÉRICA LATINA E O CARIBE (CEPAL). La república popular China y América Latina y el Caribe. Hacia una nueva fase en el vínculo económico y comercial, Junio. Santiago de Chile: CEPAL, 2011a. Disponível em: <http://eclac.org.cl >. Acesso em: out. 2011.

COMISSÃO ECONÔMICA PARA A AMÉRICA LATINA E O CARIBE (CEPAL). Panorama de la inserción internacional de la América Latina y el Caribe 2010-2011. Septiembre. Santiago de Chile: CEPAL, 2011b. Disponível em: <http://eclac.org.cl>. Acesso em: out. 2011.

COMISSÃO ECONÔMICA PARA A AMÉRICA LATINA E O CARIBE (CEPAL). Statistical Yearbook for Latin America and the Caribbean 2011. Santiago do Chile: CEPAL, 2012. Disponível em: <http://www.eclac.org/estadisticas/>. Acesso em: 02 mai. 2012.

FDI MARKETS. FDI Dataset. FDI Markets, 2012. Disponível em: <http://www.fdimarkets.com>. Acesso em: 02 fev. 2012.

FENBY, J. China's domestic economy. In: SHAMBAUGH, D. Charting China's future: domestic and international challenges. New York: Routledge, 2011.

FRANKEL, J.; ROSE, A. The endogeneity of the optimum currency area criteria. The Economic Journal, v. 108, p. 1009-1025, 1998.

FURTADO, C. Raízes do subdesenvolvimento. Rio de Janeiro: Civilização Brasileira, 2003. 
GIOVANNETTI, G.; SANFILIPPO, M. Do Chinese Exports Crowd-out African Goods? An Econometric Analysis by Country and Sector. European Journal of Development Research, v. 21, n. 4, p. 506-530, 2009.

GLOBAL TRADE INFORMATION SERVICE (GTIS). Global Trade Information Service. GTIS, 2012. Disponível em: <http://www.gtis.com/english/>. Acesso em: 01 fev. 2012.

GREENAWAY, D.; MAHABIR, A.; MILNER, C. Has China displaced other Asian countries' exports? China Economic Review, v. 19, Issue 2, June, p. 152-169, 2008.

HALPER, S. The Beijing Consensus: how China's authoritarian model will dominate the twentyfirst century. New York: Basic Books, 2010.

HERITAGE FOUNDATION. China Global Investment Tracker 2011. Heritage Foundation, 2011. Disponível em: <http://blog.heritage.org/2011/01/14/china-global-investment-tracker2011/>. Acesso em: 01 ago. 2011.

HOEKMAN, B. M.; MATTOO, A.; ENGLISH, P. Development, Trade, and the WTO: A Handbook (World Bank Trade and Development Series). Washington DC: The World Bank, 2002.

HU, A. China and the world: Assessment and prospect of the "post-crisis" era. TMD Working Paper Series, Department of International Development, University of Oxford, n. 40, 2010.

IKENBERRY, G. J. The Future of the Liberal World Order: internationalism after America. Foreign affairs, v. 90, n. 3, May/Jun, p. 56-68, 2011.

INSTITUTO DE ESTUDOS PARA O DESENVOLVIMENTO INDUSTRIAL (IEDI). A indústria de transformação por intensidade tecnológica: o desafio de crescer sem deteriorar ainda mais o saldo comercial. Carta IEDI, São Paulo, n. 454, 11 fev. 2011.

INSTITUTO DE ESTUDOS PARA O DESENVOLVIMENTO INDUSTRIAL (IEDI). O Comércio Exterior Brasileiro em 2011. Análise IEDI, São Paulo, 20 jan. 2012.

INTER AMERICAN DEVELOPMENT BANK (IADB). The world offorking paths: Latin America and the Caribbean facing global economic risks. Washington, DC: IADB, 2012.

INTERNATIONAL MONETARY FUND (IMF). Directions of Trade. Washington, DC: IMF, 2012. Disponível em: <http://elibrary-data.imf.org/>. Acesso em: 02 mai. 2012.

INTERNATIONAL MONETARY FUND (IMF). People's Republic of China. IMF Country Report, Washington, n. 10/238, July, 2010.

INTERNATIONAL MONETARY FUND (IMF). World economic outlook. September. Washington, DC: IMF, 2011. Disponível em: <http://www.imf.org/external/pubs/ft/weo/2011/02/ index.htm>. Acesso em: out. 2011.

JACQUES, M. When China rules the world. 2 ed. London: Penguin Books, 2012.

JENKINS, R. China's global expansion and Latin America. Journal of Latin American Studies, v. 42, Part 4, November, p. 809-837, 2010.

JENKINS, R.; BARBOSA, A. F. Fear for Manufacturing? China and the future of industry in Brazil and Latin America. The China Quarterly, v. 209, March, p. 59-81, 2012.

JIGLIAN, W. Does China need to change its industrializations path? In: GILL, I.; HUANG, Y.; KHARAS, H. (Eds.) East Asian visions. Washington, DC: The World Bank, 2006. 
JIGLIAN, W. Understanding and interpreting Chinese economic reform. Mason: Thomson, 2005.

KANG, D. C. China Rising: peace, power and order in East Asia. New York: Columbia University Press, 2007.

KISSINGER, H. On China. London: Penguin Press HC, 2011.

KURLANTZICK, J. Charm Offensive: how China's soft power is transforming the World. New Havend and London: Yale University Press, 2007.

LEÃO, R. P. F.; PINTO, E. C.; ACIOLY, L. (Eds.) A China na nova configuração global - impactos políticos e econômicos. Brasília: IPEA, 2011.

LEDERMAN, D.; OLARREAGA, M.; PERRY, G. (Eds.) China's and India's challenge to Latin American. Washington, DC: World Bank, 2008.

LÉLIS, M. T. C.; CUNHA, A. M.; LIMA, M. G. El desempeño de las exportaciones de China y el Brasil hacia América Latina, 1994-2009. Revista de la Cepal, n. 106, Abril, p. 57-77, 2012.

MEARSHEIMER, J. J. Imperial by Design. The National Interest, n. 111, Jan./Feb., p. 16-34, 2010. Disponível em: <http://mearsheimer.uchicago.edu/all-pubs.html>. Acesso em: set. 2011.

MINISTRY OF COMMERCE PEOPLE'S REPUBLIC OF CHINA (MOFCOM). 2010 Statistical Bulletin of China's Outward Foreign Direct Investment. Beijing: MOFCOM, 2011.

MORRISON, W. M.; LABONTE, M. China's holdings of U.S. securities: implications for the U.S. Economy. Congressional Research Service, 26 set. 2011.

NATIONAL INTELLIGENCE COUNCIL. Global Trends 2025: a transformed world. Washington, DC: National Intelligence Council, 2008.

NAUGHTON, B. The Chinese economy: transitions and growth. Cambridge, MA: The MIT Press, 2007.

NOLAN, P. China and the global economy. In: SHAMBAUGH, D. Charting China's future: domestic and international challenges. New York: Routledge, 2011.

NYE JR, J. S. N. The future of American power: dominance and decline in perspective. Foreign Affairs, v. 89, n. 6, Nov./Dec., p. 2-12, 2010.

PALMA, G. Four sources of "de-industrialisation" and a new concept of the "Dutch Disease". In: HSRC EGDI Roundtable, 21 mai. 2007.

PALMA, G. Why has productivity growth stagnated in most Latin American countries since the neo-liberal reforms? Cambridge Working Papers in Economics, n. 1030, July, 2011. Disponível em: <http://www.econ.cam.ac.uk/dae/repec/cam/pdf/cwpe1030.pdf >. Acesso em: 9 jan. 2011.

PAVITT, K. Sectoral patterns of technical change: towards a taxonomy and a theory. Research Policy, v. 13, n. 19, 1984.

PHILLIPS, N. Re-ordering the region? China, Latin America and the Western Hemisphere. European Review of Latin American and European Studies, n. 90, April, p. 89-99, 2011.

PREBISCH, R. Five Stages in My thinking on development. In MEIER, G. M.; SEERS, D. (Eds.) Pioneers in Development. Oxford: Oxford University Press, 1984. 
ROSALES, O.; KUWAYAMA, M. China y América Latina y el Caribe hacia una relación económica y comercial estratégica. Santiago de Chile: CEPAL, 2012.

ROWTHORN, R. E.; WELLS, J. R. De-industrialization and foreign trade. Cambridge: Cambridge University Press, 1987.

SACHS, J.; WARNER, A. Natural resource abundance and economic growth. Cambridge, MA: Center for International Development / Harvard Institute for International Development / Harvard University, 1997.

SALIDJANOVA, N. Going out: an overview of China's outward foreign direct investment. U.S. China Economic and Security Review Commission Research Archive, 30 mar. 2011. Disponível em: <http://www.uscc.gov/researchpapers/research_archive.php>. Acesso em: out. 2011.

SHIRK, S. L. China: fragile superpower: how China's internal politics could derail its peaceful rise. Oxford: Oxford University Press, 2007.

SINNOT, E.; NASH, J.; DE LA TORRE, A. Natural resources in Latin America and the Caribbean - Beyond Booms and Busts? Washington, DC: The World Bank, 2010.

STEIL, B., LITAN, R.E. Financial Statecraft: the role of financial markets in American foreign policy. New Haven: Yale University Press, 2006.

SUBRAMANIAN, A. The inevitable superpower: Why China's dominance is a sure thing. Foreign Affairs, Sep./Oct., p. 66-78, 2011.

UNITED NATIONS (UN). UN COMTRADE. United Nations Commodity Trade Statistics. UN, 2012. Disponível em: <http://comtrade.un.org/>. Acesso em: 05 jan. 2012.

UNITED NATIONS CONFERENCE ON TRADE AND DEVELOPMENT (UNCTAD). World investment report 2011. Geneva: UNCTAD, 2011.

UNITED NATIONS. United Nations Statistics Division. National Accounts. 2012. UN, 2012. Disponível em: <http://unstats.un.org/unsd/snaama/Introduction.asp>. Acesso em: 05 mai. 2012.

WONG, R. B. Chinese political economy and the international economy: linking global, regional and domestic possibilities. In: CALHOUN, C.; DERLUGUIAN, G. (Eds.) Aftermath - A new global economic order? New York: New York University Press, 2011.

WOOD, A.; MAYER, J. Has China de-industrialised other developing countries? QEH Working Papers Series, n. 175, June, 2010.

WORLD BANK. World Development Indicators. 2012. UN, 2012. Disponível em: <http://data. worldbank.org/indicator>. Acesso em: 01 jul. 2012.

YUFAN HAO, C. X.; WEI, G.; DITTMER, L. (Eds.) Challenges to Chinese foreign policy: diplomacy, globalization and the next world power. Lexington: The University Press of Kentucky, 2009. 